\title{
Mikati-Najjar-Sahli syndrome
}

INSERM

\section{Source}

INSERM. (1999). Orphanet: an online rare disease and orphan drug data base. MikatiNajjar-Sahli syndrome. ORPHA:2558

Mikati-Najjar-Sahli syndrome is characterized by microcephaly, hypergonadotropic hypogonadism, short stature and facial dysmorphism (a narrow forehead, hypertrophy and fusion of the eyebrows, micrognathia and pinnae abnormalities). 